\title{
Surgery, Neonatal Pediatric
}

National Cancer Institute

\section{Source}

National Cancer Institute. Surgery, Neonatal Pediatric. NCI Thesaurus. Code C19051.

Surgery on neonates 